\title{
Pattern of Childhood Malignant Tumour in the Paediatric Surgery Department of Bangabandhu Sheikh Mujib Medical University
}

\author{
Gazi Zahirul Hasan', AKM Zahid Hossain², Md. Ruhul Amin ${ }^{3}$, MTH Siddiqui', K.M. Didarul Islam ${ }^{5}$ \\ ${ }^{1}$ Assistant Professor, ${ }^{2}$ Assistant Professor, ${ }^{3}$ Associate Professor, ${ }^{4}$ Associate Professor, ${ }^{5}$ Assistant Professor, Department of Paediatric \\ Surgery, Bangabandhu Sheikh Mujib Medical University
}

\begin{abstract}
:
Background: Childhood malignancy is fast becoming an important paediatric problem in Bangladesh. They differ markedly from adult malignancy in their nature and distribution. This is a 5 years retrospective study of childhood malignant tumour as seen at the paediatric surgery department of Bangabandhu Sheikh Mujib Medical University (BSMMU). Objectives: The objective of this study is to determine the types of malignant patients admitted in the paediatric surgery department of BSMMU and also to know their age and sex distribution. Methods: This is a 5 years retrospective study from January 2005 to December 2009 in the paediatric surgery department of BSMMU, Dhaka, Bangladesh. All admitted malignant patients, aged up to 15 years diagnosed by means of histological or cytological examination included in this study. Results: Seventy (70) malignant patients were admitted during the study period, $65.7 \%$ patients were male and $34.3 \%$ patients were female with a male female ratio of 1.9:1. Fifty two (74.3\%) patients were below 5 years and eighteen (25.7\%) patients were between 5 to 15 years. The Wilms' tumour was the most common malignant tumour which accounted for $42.8 \%$. Hepatoblastoma was the second most common (24.2\%). The other malignant tumours were neuroblastoma (15.7\%), Non-Hodgkins lymphoma (5.7\%), Rhabdomyosarcoma (4.2\%), malignant fibrous histocytoma (1.4\%), Fibroscarcoma (1.4\%), Osteosarcoma (1.4\%), malignant sacrococcygeal teratoma (1.4\%), carcinoma of the rectum (1.4\%0. Conclusion: Based on the result of this study, Wilms' tumour is the commonest paediatric solid malignancy in our country. Carcinoma of the rectum may rarely occur in paediatric age group.
\end{abstract}

Key words: Frequency, malignant solid tumor, children.

[BSMMU J 2011; 4(2): 99-101]

\section{Introduction:}

Malignancy remains one of the major cause of the death in children between the age of 1-15 years ${ }^{1}$. Paediatric malignancy differ markedly from adult malignancy in their nature, distribution and prognosis ${ }^{2}$. Paediatric surgeons and oncologist face unique challenges because treatment with surgery, irradiation and chemotherapy adversely affect the childs growth and development. The incidence and type of childhood malignancy vary greatly throughout the World ${ }^{2}$. Though their incidence is lower compared with the incidence of adult malignancy, in recent years the malignancy incidence in paediatric population has dramatically increased ${ }^{3}$. Few years back, malnutrition and infectious disease was the major cause of childhood morbidity and mortality in the developing nations of the World, but now a days, childhood malignancy is beginning to contribute significantly to morbidity and mortality. This changes may understandly be due to increased awareness and use of immunization against infections diseases ${ }^{4}$.

Address of Correspondence: Dr. Gazi Zahirul Hasan, Assistant Professor, Department of Paediatric Surgery, Bangabandhu Sheikh Mujib Medical University, Dhaka, Bangladesh, Email: drgazizahirhasan@yahoo.com
Although only 2\% of all malignant tumors occur in infant and childhood, malignant solid tumour is nontheless the leading cause of death in children less than 15 years of age all over the World ${ }^{5}$. This study is a 5 years retrospective case study from January 2005 to December 2009 and it is carried out to determine the pattern of childhood malignancy admitted in the Paediatric Surgery Department of BSMMU, Dhaka, Bangladesh. BSMMU is a tertiary care hospital in Bangladesh and Paediatric Surgery department is a major referral centre for paediatric surgery patient from every corners of this country. Although exact incidence rate can not be provided by a hospital based study, this study report will be useful in some extent to show the pattern of childhood solid malignancy in our country.

\section{Methods:}

This is a retrospective case study using hospital records. All children with malignancy aged up to 15 years diagnosed by means of histological or cytological examination admitted in the Paediatric Surgery department of BSMMU from January 2005 to December 2009 were included in this study. The patient who admitted several times for redo surgery are considered as one patient. 
Special care was taken to exclude double entry. All data were checked, recorded and analysed properly. Patients were classified in to different groups according to the types of malignancy and their age and sex distribution were also analyzed in this study.

\section{Results:}

During the study period between January 2005 to December 2009, total 70 malignant patients were admitted in the Paediatric Surgery Department of BSMMU. Forty six (65.7\%) were male and twenty four (34.3\%) were female with a male female ratio of 1.9:1. Fifety two (74.3\%) patients were below 5 years and eighteen (25.7\%) patients were between 5 to 15 years. In this study, Wilms' tumor was the most prevalent. Their number was 30 (42.8\%). They were followed by hepatoblastoma 17 (24.2\%), neuroblastoma 11 (15.7\%), Non Hodgkins lymphoma 4 (5.7\%), Rhabdomyosarcoma 3 (4.2\%), Osteosarcoma 1 (1.4\%), malignant sacrococcygeal teratoma 1 (1.4\%), malignant fibrous histocytoma 1 (1.4\%), fibrosarcoma 1 (1.4\%) and carcinoma of the rectum 1 (1.4\%). The pattern of childhood malignancy and the age distribution of the affected child is shown in table $\mathrm{I}$.

Out of the 30 (42.8\%) Wilms' tumour patients, 22 (31.4\%) patients were below 5 years and 8 (11.4\%) patients were between 5 to 15 years. Twenty one (30\%) patients developed tumour on right side and nine (12.8\%) on left side and eighteen (25.7\%) patients were male and twelve (17.1\%) patients were female.
Out of the seventeen (24.2\%) hepatoblastoma patients, fourteen (20\%) patients were below 5 years and three (4.2\%) patients were between 5 to 15 years. Eleven (15.7\%) patients were male and six(5\%) patients were female.

Eleven (15.7\%) neuroblastoma patients were admitted, 8 (11.4\%) patients were below 5 years and 3 (4.2\%) patients were between 5 to 15 years, 7 (10\%) patients developed tumour on right side and 4 (5.7\%) patients developed on left side. Eight (11.4\%) patients were male and 3 (4.2\%) patients were female. Four (5.7\%) patients admitted with Non Hodgkins Lymphoma in abdominal site, three ((4.2\%) patients were below 5 years and 1 (1.4\%) patient was above 5 years. Among them 3(4.2\%) were male and $1(1.4 \%$ \} was female.

Three (4.3\%) rhabdomyosarcoma patients were admitted, 2 (2.8\%) were below 5 years and 1 (1.4\%) was above 5 years. All 3 patients were male, 1 patients developed rhabdomyosarcoma in the right thigh, 1 in the right inguinal region and 1 in the bladder prostatic site.

One (1.4\%) patient admitted with malignant fibrous histocytoma in the left hand, he was male and age was $21 / 2$ years. Two other male patients of $4 \frac{1}{2}$ years and 3 years admitted with fibrosarcoma in the neck and osteosarcoma in leg respectively. One female patient, aged $61 / 2$ years admitted with malignanat sacrococcygeal teratoma and another female patients of 13 years admitted with carcinoma of the rectum.

\section{Table-I}

Prevalance of childhood cancer and the age of distribution of the affected child over the period January 2005 to December 2009. $(n=70)$

\begin{tabular}{lccc}
\hline Cancer & No (\%) & $\begin{array}{c}<5 \text { years } \\
\text { (No. \& Percentage) }\end{array}$ & $\begin{array}{c}5-15 \text { years } \\
\text { (No. \& Percentage) }\end{array}$ \\
\hline 1. Wilm's tumour & $30(42.8 \%)$ & $22(31.4 \%)$ & $8(11.4 \%)$ \\
2. Hepatoblastoma & $17(24.2 \%)$ & $14(20 \%)$ & $3(4.2 \%)$ \\
3. Neuroblastoma & $11(15.7 \%)$ & $8(11.4 \%)$ & $3(4.2 \%)$ \\
4. Non Hodgkins lymphoma & $4(5.7 \%)$ & $3(4.2 \%)$ & $1(1.4 \%)$ \\
5. Rhabdomyosarcoma & $3(4.2 \%)$ & $2(2.8 \%)$ & $1(1.4 \%)$ \\
18. Osteosarcoma & $1(1.4 \%)$ & $1(1.4 \%)$ & 0 \\
9. Malignant Sacrococcygeal teratoma & $1(1.4 \%)$ & 0 & $1(1.4 \%)$ \\
10. Carcinoma of the rectum & $1(1.4 \%)$ & 0 & $1(1.4 \%)$ \\
\hline
\end{tabular}




\section{Discussion:}

This study showed that 70 malignant patients were admitted in 5 years between January 2005 to December 2009 in the Paediatric Surgery Department of BSMMU. This gives an average of 14 patients per year. This result is almost similar to other reports of the Asian subcontinent. Their report was 12.8 patients per years ${ }^{4}$.

In this study, 46 (65.7\%) patients were male and 24 (34.3\%) patients were female with a male female ratio of 1.9:1 which meets with the Asian and African trend ${ }^{6,7}$, but differs from the trend in western countries where the male to female ratio is $1: 1^{8}$.

Fifty two (74.3\%) patients were below 5 years and 18 (25.7\%) patients were between 5 to 15 years. This study correlates with the other studies ${ }^{6,8}$. The most common malignant tumour in this study was Wilms' tumour. It is 42.8\%. It correlates with some of the studies done in Asia ${ }^{6}$. In some African studies, Wilms tumour is also commonest ${ }^{9}$ but most of the African and American reports showed that either lymphoma or rhabdomyosarcoma are more common ${ }^{2,8,10}$. Retinoblastoma and brain tumour are also common in some studies ${ }^{6}$ but in BSMMU, Retinoblastoma and brain tumour are admitted in opthalmology and neurosurgery department respectively. Although hepatoblastoma is rare variety in most of the studies conducted outside this country, it is the second most common tumour (24.2\%) in our study. More studies are required to find out the cause of increase incidence of this tumor in our country. Neuroblastoma comprises $15.7 \%$ of the tumour of this study. It also differs from other studies. It is a rare varient in most of the studies conducted in Asia, Africa and Europe but this report shows that this is not very rare in our country. Lymphoma and rhabdomyosarcoma comprises $5.7 \%$ and $4.2 \%$ of the tumour of this study respectively. It actually not reflect the total picture of our country because most of the rhabdomyosarcoma involving the limbs treated in orthopaedic ward and the lymphoma patients are also treated in the Paediatric haemato-oncology department. One malignant sacrococcygeal teratoma patient is also included in this study. Most of the sacrococcygeal teratoma patients come to us in benign form in early age. This unfortunate patient came to us at the age of $6 \frac{1}{2}$ years which indicates the lake of awareness of their family. One patient came to us with carcinoma of the rectum at the age of 13 years. Although carconoma of the rectum is a rare variant in children but this study showed that no age is absolutely immune to develop this disease.

\section{Conclusion:}

From this study, it may be concluded that Wilms' tumour is the commonest childhood solid malignancy and Hepatoblastoma is second most common in our country. Carcinoma of the rectum may rarely occur in children. So we must consider this disease when a child comes to us with per rectal bleeding

\section{References:}

1. American cancer society. Cancer facts and figures 2005. reviewed on March 29, 2005, accessed at http:www.cancer.org.

2. Huda M. Haroun, Mohammed S. Mahfuz, Ahmed M. Elhaj. Patterns of childhood cancer in children admitted to the institute of nuclear medicine, molecular biology and oncology, wad Medani, Gegira state; J Family and Community Medicine 2006;13(2): 71-74.

3. Bleyer WA. 'Cancer in older adolescents and young adults. Diagnosis, treatment, survival and importance of Clinical trial. Medical and Paediatric Oncology 2002; 38 (1): 1-10.

4. Sharma S, Mishara K, Againal S, Khanna G. Solid tumours of childhood. Ind J of Paed 2004;71:501-4.

5. Qureshi S, Qudeer N. 'The current trend of malignant solid tumour in children hospital. J Pak Inst Med Sci 1990;32 (2):65-7.

6. Farjana Memon, Shankar lal Rathi, Manzoor H. Memon. 'Pattern of solid paediatric malignant neoplasm at Lumhs, Jamshoro, Pakistan. J Ayub Med Coll, Abbottabad 2008; 19 (4): 55-57.

7. Nkanga NK. Paediatric Solid malignant tumors in Zimbabwe. Cent Afr J Med1989; 35 (10): 496-501.

8. Gonzalez JR, Fernandej E, Toledo JS. 'Trends in children cancer incidence and mortality in catalomia, Spain, 19751998. Eur J Cancer Prev 2004; 13 (1):47-51.

9. Modupeola Omotara Samaila. Malignant tumors of childhood in Zaria, Nigeria. Afr J of Paed Surg 2009; 6 (1): 19-23.

10. Naanlep M Tanko,Godwin O Echejoh, Nanfwang A Mannasseh, Mafala B Mandong. Paediatric Solid tumour in Nigerian children: A changing pattern. Afr J of Paed Surg 2009;6(1): 7-10. 